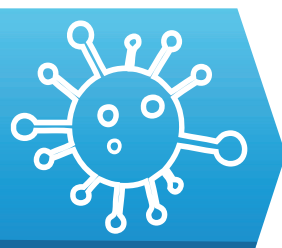

INFECTIOUS DISEASESS

\section{Long-term antiviral hepatitis $C$ treatment associated with Rods and Ring Cytoplasmic antibodies}

Vasile Feldrihan $^{1}$, Andreea Benea ${ }^{2}$, Monica Lia Junie ${ }^{3}$
1) Functional Biosciences, Immunology and Allergy Department, Iuliu Hatieganu University of Medicine and Pharmacy, Cluj-Napoca, Romania

2) Immunology Laboratory of Prof. Dr. O. Fodor Institute of Gastroenterology and Hepatology, Cluj-Napoca, Romania

3) Molecular Sciences, Microbiology Department, Iuliu Hatieganu University of Medicine and Pharmacy, ClujNapoca, Romania
DOI: 10.15386/cjmed-996

Manuscript received: 16.02 .2018 Received in revised form: 15.06 .2018 Accepted: 06.07.2018

Address for correspondence: vasile.feldrihan@gmail.com

\begin{abstract}
Aim. Clinical description of a patient diagnosed with chronic hepatitis $\mathrm{C}$ virus infection, which associated a rare anti-cytoplasmic pattern, known as "Rods and Ring".

Method. Clinical case report.

Results. A 76-year old female patient with chronic hepatitis C virus infection under treatment for several months with pegylated Interferon-Ribavirin (started eight months ago) presented for clinical and biological evaluation of the therapeutic response.

Conclusion. This is the first reported clinical case of a patient with cytoplasmic filamentous rods and rings autoantibodies associated with chronic hepatis $\mathrm{C}$ from the Clinical Hospital IRGH Prof. Dr. O. Fodor Cluj-Napoca, Romania. The presence of these antibodies appears to be triggered by antiviral therapy. Although these are newly identified antibodies, they could be used as serological markers for detecting patients at risk of developing associated autoimmune pathologies or nonresponders to the antiviral therapy. Likewise, their detection could identify patients with occult hepatitis $\mathrm{C}$ infection.
\end{abstract}

Keywords: hepatitis $\mathrm{C}$ virus infection; autoantibodies, rods and ring pattern

\section{Introduction}

Very often, chronic hepatitis C virus infection (HCV) associates immune dysregulation, manifested as extra-hepatic autoimmune phenomena [1,2]. In this scenario, long-term treatment with doubletherapy peg-IFN-RBV may exacerbate these pre-existing conditions. Any suspicion of such a pathology should be raised on clinical aspects and subsequently confirmed by serological investigations. Appropriate immunological tests for autoimmune manifestations are mainly related to indirect immunofluorescence analysis (IIF) for detection and measuring the patients' circulating autoantibodies. Among these, a major role have antinuclear antibodies with various patterns, depending on the location of the intracellular antigen.

Cytoplasmic RR autoantibodies identified by IIF on HEp-2 cell substrate occur with a high specificity in 0.8$5 \%$ of patients undergoing long-term antiviral double peg-IFN/RBV therapy $[3,4]$. There are also studies that identify their presence in up to $40 \%$ of patients that undergo treatment with IFN/RBV
$[5,6]$. Findings from recent years have not succedeed in identifying the presence of these antibodies in patients with $\mathrm{HCV}$ prior to IFN-RBV antiviral therapy or in patients with other medical conditions. Initially, they appear in serum around the sixth month of antiviral therapy and then persist in a plateau-like trend in the next twelfth month. Upon completion of treatment, the titers of anti-RR antibodies decrease in half of the patients, but still remain elevated in the other half.

There are two studies that have revealed a higher frequency of these anti$R R$ antibodies in patients with a relapse phase of the disease and non-responder to IFN/RBV therapy, especially in those who experience the reoccurrence of the circulating virus (perhaps through certain spontaneous mutations) after initially successful therapy $[6,7]$.

From a pathogenetic perspective, the antigen recognized by these anti-RR antibodies is represented by inosine5 '-monophosphate dehydrogenase 2 (IMPDH2), which is the key enzyme in the biosynthesis of purine bases (guanosine triphosphate) involved in DNA synthesis 
[8]. Inhibition of guanosine triphosphate (GTP) and cytidine triphosphate (CTP) biosynthetic pathways induce the cell to assemble in a rod/ring structures, which consist of IMPDH2 [9]. Ribavirin is a direct inhibitor of IMPDH2, thus being able to induce the formation of RR structures in vitro and in vivo. Subsequently, in the presence of IFN/ RBV therapy, these structures induce the generation of anti-RR antibodies [10-13].

\section{Case presentation}

We have studied the case of a 76-year-old female patient, retired, diagnosed in the past with $\mathrm{HCV}$ infection and other age-related cardio-vascular diseases (hypertension), who was admitted to the IRGH Clinical Hospital Prof. Dr. O Fodor for assessment of the therapeutic response to antiviral double therapy. Over the past eight months the patient had been treated with IFN-pegylatribavirin combination without any improvement in clinical and bio-humoral parameters. Prior to antiviral therapy, she had no autoimmune pathologies, all immunological tests being negative.

Clinical examination upon admisson revealed jaundice and signs of age-related heart disease, as well as osteo-articular arthrosis type disease, and recently identified signs of Hashimoto's and mixed connective tissue diseases.

Laboratory investigations revealed the full blood count within normal parameters (leucocytes $=4 \times 10^{3} / \mu 1$, erythrocytes $=4.37 \times 10^{6} / \mu \mathrm{l}$ ) with slightly decreased platelets number to $120 \times 10^{3} / \mu \mathrm{l}$. Biohumoral: total bilirubin= 2.1 (0.1-1.2), direct bilirubin=1.05 (0-0.52), Gamma GT $=53$ (7-32), ALT= 51 (5-45 U/1), AST=64 (5-45 U/1). Abdominal ultrasound examination was suggestive for liver cirrhosis Child-Pugh class A.

Immunological test, such as Enzyme-Linked Immunosorbent assay (ELISA) showed negative results for antimitochondrial antibodies (AMA), anti-smooth muscle antibodies (SMA), anti-liver-kidney microsmal (LKM) and anti-neutrophil cytoplasmic antibody (PANCA); however, antinuclear antibodies (ANA) were positive.

Additionally, indirect immunofluorescence analysis was performed using HEp-2 cells as a substrate (INOVA Diagnostics, San Diego, CA, USA) and reading with a Zeiss Axio Imager (Carl Zeiss Inc., Germany). The assay revealed the presence of circulating ANA with a titer of 1:320 and cytoplasmic "rods and rings" pattern (Figure 1).

Other immunological tests revealed: Alphafetoprotein $=13.9 \mathrm{ng} / \mathrm{ml}(0-9.5)$, Crioglobulin ++ , and Hyper IgM = $276 \mathrm{mg} / \mathrm{ml}$ (40-230), Hbs antigen = negative, $\mathrm{HBc}$ antibody $=$ positive and undetectable anti-delta virus antibodies.

\section{Discussion}

We report here the case of a 76-year-old female patient, known with chronic hepatitis $\mathrm{C}$ virus infection and age-related pathology, who associates in evolution a very rare pattern of anti-RR cytoplasmic antibodies after antiviral therapy.These anti-RR antibodies were correlated with the occurrence of autoimmune manifestations and also with unfavorable evolution of the disease even under the antiviral therapy. The data presented in this report show that these RR antibodies are strongly associated with the $\mathrm{HCV}$ chronic infection, and their presence is induced by combined IFN/RBV therapy, the incidence increasing in proportion to the duration of treatment.

Although the patient did not present ANA prior to initiating the antiviral therapy, circulating autoantibodies reactive against cytoplasmic antigens were detected within eight months of sustained therapy. At the same time, when presented for evaluation, the patient associated manifestations of mixed connective tissue disease. To our knowledge, this is the only published case of HCV therapyassociated RR antibodies from Romania.
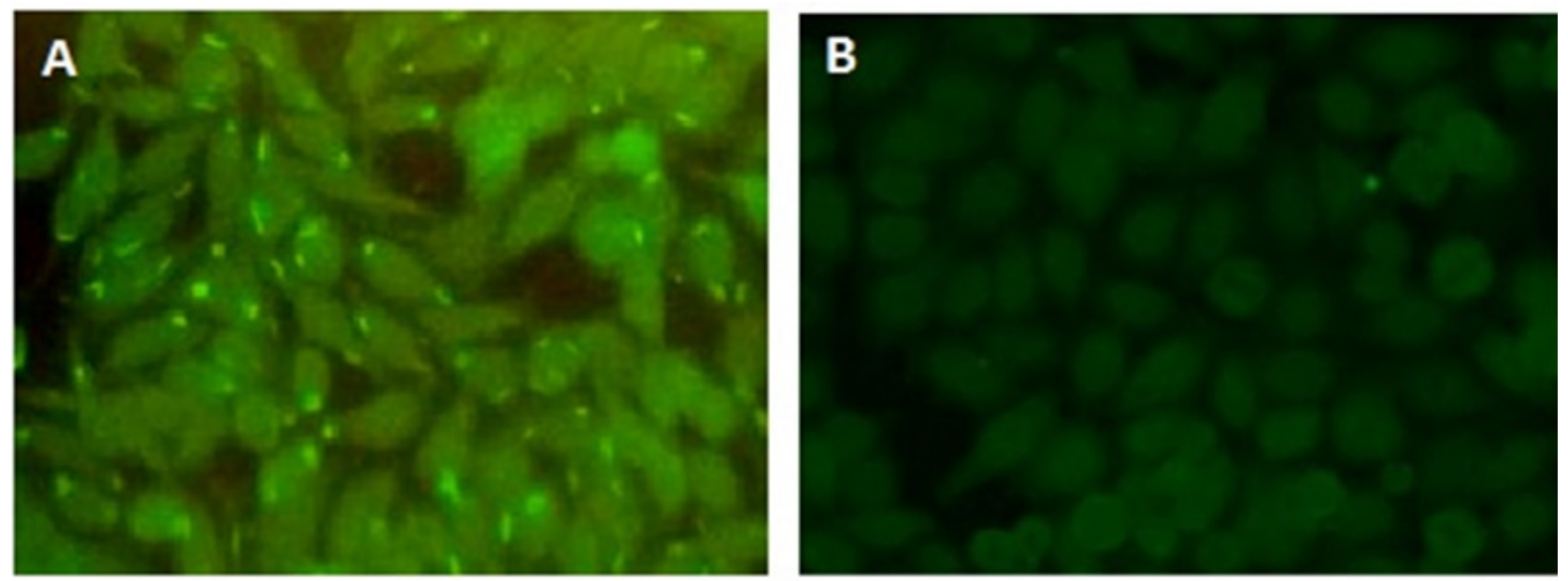

Figure 1. A. Cytoplasmatic rods and rings of HEp-2 cells in the serum from the patient with hepatitis $\mathrm{C}$ virus infection (x100); and $\mathrm{B}$. serum from a healthy person/negative control (x100). 
Rods and rings autoantibodies have become of increasing interest especially in patients with known history of $\mathrm{HCV}$ infection and who have undergone combined IFN/RBV therapy. The generation of these anti$\mathrm{RR}$ antibodies appears to be dependent on the inhibition of IMPDH2 enzyme, which plays a key role in the synthesis of purine bases and DNA. The blocking of the enzyme function appears to be closely correlated with long-term administration of Ribavirin in the form of IFN-RBV antiviral combination therapy for HCV infection. Thus, in the presence of viral modifications and IFN therapy, the cytoplasmic rods and rings seem to be recognized as antigenic structures, thereby inducing the generation of autoantibodies [10-13].

In terms of their clinical significance, although previous reports showed no relationship between this pattern and demographic parameters, duration of diagnosis of $\mathrm{HCV}$, treatment response pattern, $\mathrm{HCV}$ genotype or viral load, all previous studies have been found a strong association between anti RR antibodies response and HCV patients treated with with IFN/RBV [14-18]. Additionally, other studies have indicated a link between anti-RR and non-responsiveness or relapse in American and Italian HCV patient cohorts [6,7].

Our observations correlated with previous studies, lead us to the hypothesis that the occurrence of anti-RR antibodies represents a model of drug-induced immunological tolerance loss, having as main trigger the specific antiviral treatment with pegIFN and Ribavirin [19]. Thus, the early identification of these patients by IIF screening tests for the detection of anti-RR antibodies could be an indicator in early recognition of the patients with a relapse phase of HCV. Likewise, this unique exemple of autoantibody generation in human could be a very useful screening tool for identifying patients at risk of developing autoimmune conditions followed viral therapy, as well as to identify individuals with unnoticed HCV infection.

In addition, a better identification and characterization of this novel set of antibodies-associated $\mathrm{HCV}$ infection and therapy can help a better understanding of immuno-pathomechanism, thus potentially improving the arsenal of diagnostic test in the future.

\section{Acknowledgements}

We sincerely thank Prof. Dr. Deleanu Diana and Dr. Erica Chiorean for their assistance.

\section{Ethics approval and consent to participate}

A written informed consent was signed by the patient for the publication of this case report and any accompanying images.

\section{References}

1. Vergani D, Mieli-Vergani G. Autoimmune manifestations in viral hepatitis. Semin Immunopathol. 2013;35:73-85.

2. Ferri S, Muratori L, Lenzi M, Granito A, Bianchi FB, Vergani D. HCV and autoimmunity. Curr Pharm Des. 2008;14:1678-1685.
3. Afsharzadeh F, Bokharaei-Salim F, Esghaei M, Monavari SH, Merat S, Poustchi H, et al. The Presence of Autoantibodies to Cytoplasmic Rod and Ring Particles in the Serum of Patients with Chronic Hepatitis C Virus Infection. Hepat Mon. 2016;16

4. Stinton LM, Myers RP, Coffin CS, Fritzler MJ. Clinical associations and potential novel antigenic targets of autoantibodies directed against rods and rings in chronic hepatitis $\mathrm{C}$ infection. BMC Gastroenterol. 2013;13:50.

5. Calise SJ, Bizzaro N, Nguyen T, Bassetti D, Porcelli B, Almi P, et al. Anti-rods/rings autoantibody seropositivity does not affect response to telaprevir treatment for chronic hepatitis $\mathrm{C}$ infection. Auto Immun Highlights. 2016;7:15.

6. Covini G, Carcamo WC, Bredi E, von Mühlen CA, Colombo M, Chan EK. Cytoplasmic rods and rings autoantibodies developed during pegylated interferon and ribavirin therapy in patients with chronic hepatitis C. Antivir Ther. 2012;17:805-811.

7. Carcamo WC, Ceribelli A, Calise SJ, Krueger C, Liu C, Daves $\mathrm{M}$, et al. Differential reactivity to IMPDH2 by anti-rods/rings autoantibodies and unresponsiveness to pegylated interferonalpha/ribavirin therapy in US and Italian HCV patients. J Clin Immunol. 2013;33:420-426.

8. Keppeke GD, Andrade LE, Grieshaber SS, Chan EK. Microinjection of specific anti-IMPDH2 antibodies induces disassembly of cytoplasmic rods/rings that are primarily stationary and stable structures. Cell Biosci. 2015;5:1.

9. Keppeke GD, Calise SJ, Chan EK, Andrade LE. Assembly of IMPDH2-based, CTPS-based, and mixed rod/ring structures is dependent on cell type and conditions of induction. J Genet Genomics. 2015;42:287-299.

10. Seelig HP, Appelhans H, Bauer O, Blüthner M, Hartung K, Schranz P, et al. Autoantibodies against inosine-5' -monophosphate dehydrogenase 2--characteristics and prevalence in patients with HCV-infection. Clin Lab. 2011;57:753-765.

11. Keppeke GD, Satoh M, Ferraz ML, Chan EK, Andrade LE. Temporal evolution of human autoantibody response to cytoplasmic rods and rings structure during anti-HCV therapy with ribavirin and interferon- $\alpha$. Immunol Res. 2014;60:38-49.

12. Probst C, Radzimski C, Blöcker IM, Teegen B, Bogdanos DP, Stöcker W, et al. Development of a recombinant cell-based indirect immunofluorescence assay (RC-IFA) for the determination of autoantibodies against "rings and rods"-associated inosine-5'monophosphate dehydrogenase 2 in viral hepatitis C. Clin Chim Acta. 2013;418:91-96.

13. Calise SJ, Carcamo WC, Ceribelli A, Dominguez Y, Satoh M, Chan EKL. Antibodies to Rods and Rings. In: Gershwin YSLME, editor. Autoantibodies (Third Edition) San Diego: Elsevier; 2014. pp. 19; 161-168.

14. Novembrino C, Aghemo A, Ferraris Fusarini C, Maiavacca R, Matinato $\mathrm{C}$, Lunghi $\mathrm{G}$, et al. Interferon-ribavirin therapy induces serum antibodies determining 'rods and rings' pattern in hepatitis C patients. J Viral Hepat. 2014;21:944-949.

15. Keppeke GD, Nunes E, Ferraz ML, Silva EA, Granato C, Chan EK, et al. Longitudinal study of a human drug-induced model of autoantibody to cytoplasmic rods/rings following HCV therapy with ribavirin and interferon- $\alpha$. PLoS One. 2012;7:e45392.

16. Calise SJ, Keppeke GD, Andrade LE, Chan EK. Anti-rods/ rings: a human model of drug-induced autoantibody generation. Front Immunol. 2015;6:41.

17. Stinton LM, Myers RP, Coffin CS, Fritzler MJ. Clinical associations and potential novel antigenic targets of autoantibodies directed against rods and rings in chronic hepatitis $\mathrm{C}$ infection. 
BMC Gastroenterol. 2013;13:50.

18. Keppeke GD, Calise SJ, Chan EK, Andrade LE. Anti-rods/ rings autoantibody generation in hepatitis $\mathrm{C}$ patients during interferon- $\alpha$ /ribavirin therapy. World J Gastroenterol. 2016 Feb
14;22:1966-1974.

19. Barry RM, Bitbol AF, Lorestani A, Charles EJ, Habrian CH, Hansen JM, et al. Large-scale filament formation inhibits the activity of CTP synthetase. Elife. 2014;3:e03638. 